\title{
A Incidência do Orçamento Empresarial em Indústrias de um Distrito Industrial
}

\author{
Carlos Eduardo de Oliveira ${ }^{1}$
}

\begin{abstract}
Resumo
O objetivo deste estudo foi verificar a incidência do orçamento empresarial em indústrias de um distrito industrial. Esta pesquisa descritiva adotou como procedimento de pesquisa o levantamento amostral ou survey, apresentando um estudo elaborado nas indústrias do Distrito Industrial I do município de Bauru - SP, cadastradas no CIESP - Diretoria Regional Bauru. As perguntas do questionário estão organizadas em blocos relacionados aos objetivos específicos e investigando as características das indústrias. Os resultados da pesquisa mostram que o orçamento empresarial é utilizado por $57 \%$ das indústrias pesquisadas, o que indica que nem todas as empresas consideram o orçamento empresarial como um instrumento de mensuração quantitativa e de gestão, buscando torná-lo seu instrumento de integração, condução e um meio eficiente de atingir os objetivos da empresa. Em termos específicos, esta pesquisa apresenta que os motivos principais que levaram a maioria das empresas a utilizar o orçamento, é o fato de auxiliar na conquista de vantagem competitiva em relação aos concorrentes e por proporcionar melhoramentos no processo de tomada de decisões.
\end{abstract}

Palavras-chave: Planejamento Empresarial; Orçamento Empresarial; Instrumentos de Controle.

\section{The Incidence of the Business Budget in Industries of an Industrial District}

\begin{abstract}
The objective of this study was to verify the incidence of the business budget in industries of an industrial district. This descriptive study procedure adopted as the survey sample and survey, presenting a study conducted in the industries of the Industrial District I of Bauru $\mathrm{SP}$, registered in CIESP - Regional Board Bauru. The questionnaire is organized into blocks related to specific goals and investigating the characteristics of industries. The survey results show that the corporate budget is used for $57 \%$ of the industries surveyed, indicating that not all companies consider the corporate budget as an instrument of quantitative measurement and management, trying to make it an instrument of integration, driving and an efficient means of achieving corporate goals. Specifically, this research shows that the main reasons that led most companies to use the budget, is that help deliver competitive advantage over competitors and to provide improvements in the process of decision making.

Keywords: Business Planning; Business Budget; Control Devices.
\end{abstract}

\footnotetext{
${ }^{1}$ Doutor em Economia (UFU), Mestre em Engenharia de Produção (UNESP), Graduado em Ciências Contábeis (ITE). Professor Adjunto da Universidade Federal de Uberlândia (UFU), Faculdade de Ciências Integradas do Pontal (FACIP/UFU), Curso de Graduação em Ciências Contábeis. E-mail: carlos.oliveira@ufu.br.
} 


\section{Introdução}

A evolução da sociedade brasileira é marcada por fatos que levam a humanidade a se adaptar a novos cenários, tanto políticos como empresariais e sociais. Nos dois últimos séculos, o mundo viveu duas grandes guerras, mudanças culturais, mudanças tecnológicas e crescimento populacional. Houve considerável evolução no século XX do modelo capitalista de organização econômica e atualmente convivemos com a globalização dos negócios, tornando-se indispensável o planejamento e a correta utilização dos recursos oriundos da natureza e da boa condução dos negócios.

Existe atualmente no Brasil grande mortalidade de empresas com pouco tempo de funcionamento. Uma das principais causas da mortalidade das empresas é a deficiência no planejamento dos negócios. Pode-se considerar que a missão e os objetivos econômicos estão diretamente relacionados com a sobrevivência das empresas no atual ambiente competitivo, onde os gestores deverão possuir informações relevantes sobre os estados futuros desejados.

O planejamento, a execução e o controle da empresa tornam-se fundamentais no atual ambiente empresarial, onde formular estratégias realistas para alcançar os objetivos de curto e longo prazo, em muitas empresas, se constitui em ações de pouca compreensão pelos gestores. Considerando que mensurar quantitativamente significa medir e avaliar com rigor a quantidade ou o valor de alguma coisa, o orçamento empresarial é o instrumento de mensuração quantitativa do planejamento. Nesse contexto, o orçamento deve abranger a empresa como um todo, facilitando as diversas tomadas de decisões presentes sob a visão do futuro, proporcionando a comunicação entre os departamentos e suas respectivas contribuições aos planos de ação. A execução do orçamento empresarial de acordo com seus parâmetros, produzirá resultados operacionais que mensurados em termos econômicos e financeiros possibilitará à empresa atingir sua missão e propósitos básicos. O planejamento é fundamental para o sucesso de qualquer meta a ser atingida pelo ser humano.

Considerando o orçamento empresarial como um instrumento quantitativo importante para a gestão dos negócios, apresenta-se como objetivo principal deste trabalho investigar se as indústrias do Distrito Industrial I do município de Bauru elaboram o orçamento empresarial. Daí a importância deste trabalho sobre o "modus operandi", o que torna o trabalho relevante, gerando uma contribuição à tomada de decisão e na utilização de métodos quantitativos nas indústrias da região. 
Tem-se o objeto de estudo acerca das indústrias situadas no município de Bauru, pertencentes ao Distrito Industrial I, compreendida pela jurisdição do Centro das Indústrias do Estado de São Paulo (CIESP), Diretoria Regional de Bauru. A região geográfica escolhida para o estudo vai de encontro às missões do CIESP - Diretoria Regional de Bauru, no que diz respeito a promover estudo de problemas que interessem as classes produtoras, notadamente a indústria; fomentar o intercâmbio entre indústrias e associações representativas, buscando a divulgação de conhecimentos úteis à compreensão de sua missão à sociedade e cooperar com os poderes públicos no estudo e soluções de problemas que se relacionem com a indústria; as empresas a serem pesquisadas estão no município de Bauru, estado de São Paulo, o que facilitará a obtenção dos dados; é assunto que contribuirá significativamente para a região, além de grande relevância para o setor industrial.

Este estudo está estruturado em cinco seções. A primeira seção é composta desta introdução; a segunda seção apresenta a plataforma analítica composta de alguns aspectos do orçamento empresarial; a terceira seção é composta dos procedimentos metodológicos; a quarta seção apresenta os resultados do estudo e a quinta seção apresenta as considerações finais do estudo.

\section{Plataforma analítica: alguns aspectos acerca do Orçamento Empresarial}

A gestão orçamentária corresponde a um conjunto de esforços buscando maximizar os resultados. Nota-se convergência dos autores pesquisados em relação ao conceito dado por eles ao orçamento. Kohler (1970) define orçamento como um plano financeiro que serve para estimativa e controle das operações futuras. Heckert e Willson (1967) comentam que o orçamento empresarial pode ser definido como um plano coordenado de ações financeiras para a empresa executar. Sanvicente e Santos (1983) afirmam que o orçamento representa a expressão quantitativa, em unidades físicas, medidas de tempo, valores monetários, dos planos elaborados para o período subsequente, em geral doze meses. Já Sobanski (2000) entende que o planejamento orçamentário compreende o instrumento mais detalhado da organização empresarial que integra as quantificações das ações e resultados. Hoji (2004) comenta que o orçamento reflete quantitativamente as ações e políticas da empresa através de um conjunto integrado de orçamentos. Anthony e Govindarajan (2002) classificam o orçamento como um tipo de controle gerencial, um instrumento importante para o planejamento e controle das empresas no curto prazo, representando uma fatia do plano 
estratégico da empresa, estando sua operacionalização fortemente baseada em centros de responsabilidade e na segregação entre variáveis controláveis e não controláveis.

O orçamento liga as diferentes áreas da empresa, conectando planejamento estratégico com o tático e operacional. O orçamento, para Passarelli (2003), constitui-se em um método dinâmico e flexível que facilita o trabalho de todos e favorece decididamente a consecução dos objetivos da empresa. Nota-se que o orçamento é um instrumento de mensuração que engloba todos os componentes quantificáveis da empresa, exigindo a participação de todos os colaboradores, tornando-se peça fundamental para a tomada de decisão nos níveis estratégico, tático e operacional.

A análise dos fatores externos é tão importante quanto à dos elementos internos da organização. Meyer (1969) já ressaltava que a gestão orçamentária depende dessas previsões e que os responsáveis, a partir delas, recebem atribuições para um período limitado em valor e quantidade e que em períodos regulares, é efetuado um confronto do planejado com o realizado, a fim de realçar as diferenças que se verificarem. Isso mostra a importância do controle, permitindo a identificação das variações de todos os componentes do orçamento e das necessidades de tomada de decisão nos itens que sofreram as mais consideráveis divergências em relação ao orçado. Tung (1975) reforça a necessidade de controle nas empresas, afirmando que o orçamento possui duas funções principais. A primeira função é funcionar como um plano que engloba os fatores futuros da operação e os exprime em termos econômico-financeiros, para que sobre eles possa atuar a segunda função - o controle.

O orçamento foi utilizado inicialmente na administração pública das principais civilizações ocidentais. A origem da palavra orçamento, de acordo com Lunkes (2008), devese aos antigos romanos, que usavam uma bolsa de tecido chamada de fiscus para coletar os impostos. Na França, entre os anos de 1400 e 1450, o termo bouge ou bougette, originado do latim bulga, era o termo utilizado para orçamento. O século XIX foi importante para o desenvolvimento das práticas orçamentárias hoje conhecidas.

Nas organizações privadas, o orçamento foi inicialmente utilizado, segundo Zdanowicz (1983), por Brown, gerente financeiro da Du Pont de Memours, nos Estados Unidos, em 1919. Passarelli (2003) comenta que alguns especialistas situam em 1923, data da publicação do livro Budgetary Control, de J. O. McKinsey, o início da era de real difusão da técnica orçamentária entre as empresas privadas. Sua aplicação inicial dava ênfase à previsão de despesas, principalmente as despesas de propaganda e programas de vendas. Este limitado 
conceito inicial foi logo expandido de forma a cobrir todos os demais aspectos quantificáveis da empresa. Somente a partir de 1940 o orçamento passa a ser foco de estudo no Brasil, porém as empresas brasileiras somente começam a utilizá-lo a partir de 1970.

Inicialmente, o orçamento tinha como finalidade a projeção dos resultados e o seu controle. Posteriormente, privilegiou-se a revisão contínua do orçamento, eliminando os dados de períodos já concluídos e inserindo dados futuros. A terceira etapa contempla o orçamento com base zero, sendo os dados projetados e, da estaca zero, inicia-se cada período, efetua-se a mensuração, e os dados são zerados para o período seguinte. Na etapa seguinte, o orçamento flexível entra em destaque, projetando o orçamento em vários níveis de atividade, apurando os custos em qualquer nível. Já o orçamento por atividades utiliza direcionadores para estimar e controlar os resultados, sendo uma extensão do custeio baseado por atividades. Finalmente, o orçamento perpétuo avalia a relação causa-efeito na definição dos recursos a serem utilizados. Com o passar do tempo, os métodos orçamentários passaram a acompanhar as necessidades dos modernos sistemas de gestão, que utilizam outros métodos, os mais conhecidos, o orçamento padrão, orçamento de tendência e o orçamento incremental.

O sistema orçamentário deverá integrar-se com os demais sistemas, atingindo toda a estrutura organizacional, definidos em seus níveis hierárquicos e em seus aspectos por área de responsabilidade. O orçamento tem objetivos fundamentais, divididos nos aspectos do Planejamento, Coordenação, Comunicação, Motivação, Controle e Avaliação. O Quadro 1 descreve os objetivos de cada aspecto.

Para que a empresa possa alcançar os objetivos propostos, cada elemento da organização deverá estar comprometido com suas responsabilidades. Tung (1975) define que se não levar em conta as motivações e disposições dos funcionários envolvidos e se não conseguir desenvolver entre eles a participação voluntária e consciente na execução e implementação do orçamento, torna-se praticamente impossível alcançar o resultado desejado.

Quadro 1 - Descrição dos objetivos do orçamento

\begin{tabular}{|c|l|}
\hline Objetivos & \multicolumn{1}{|c|}{ Descrição } \\
\hline Planejamento & $\begin{array}{l}\text { Auxiliar e programar as atividades de um modo lógico e sistemático que corresponde à } \\
\text { estratégia de longo prazo da empresa. }\end{array}$ \\
\hline Coordenação & $\begin{array}{l}\text { Ajuda a coordenar as atividades das diversas partes da organização e garantir a } \\
\text { consistência dessas ações. }\end{array}$ \\
\hline Comunicação & $\begin{array}{l}\text { Informar mais facilmente os objetivos, oportunidades e planos da empresa aos diversos } \\
\text { gerentes de equipes. }\end{array}$ \\
\hline Motivação & Fornecer estímulo aos diversos gerentes para que atinjam metas pessoais e da empresa. \\
\hline Controle & Controlar as atividades da empresa por comparação com os planos originais, fazendo \\
\hline
\end{tabular}

ReFAE - Revista da Faculdade de Administração e Economia, v. 9, n. 1, p. 150-167, 2018 
\begin{tabular}{|c|l|}
\hline & ajustes onde necessário. \\
\hline Avaliação & $\begin{array}{l}\text { Fornecer bases para a avaliação de cada gerente, tendo em vista suas metas pessoais e as } \\
\text { de seu departamento. }\end{array}$ \\
\hline
\end{tabular} Fonte: Adaptado de Brookson (2000).

É de fundamental importância, segundo Oliveira (2008), para a elaboração das peças orçamentárias, que o gestor do orçamento empresarial tenha em mãos as premissas básicas necessárias para o início da integração das informações obtidas. Serão apresentados a seguir, conceitos sobre o orçamento de vendas, orçamento de produção, orçamento das despesas operacionais, orçamento das despesas financeiras, orçamento de caixa e o orçamento das demonstrações financeiras.

Para Oliveira (2008), a elaboração do orçamento empresarial encerra-se com a análise financeira. A diretoria deve, então, aprovar o orçamento, sugerir mudanças ou reprová-lo. A responsabilidade pela integração dos diversos orçamentos no orçamento-mestre, conhecido como orçamento empresarial é do diretor de orçamentos. Muitas vezes, o encarregado da controladoria ou do departamento financeiro é o responsável pelo orçamento empresarial nas empresas de médio e pequeno porte. Esse profissional deve distribuir, após aprovado pela diretoria, os respectivos orçamentos aos seus departamentos, antes do início do período orçamentário. Passarelli (2003) esclarece que, na medida em que o período orçamentário vai se cumprindo com a apuração dos resultados reais, variações mais ou menos importantes tendem a se manifestar e, dependendo da magnitude dessas variações, os resultados orçados tendem a sofrer um desvio da realidade e as revisões desse orçamento passam a ser fundamentais para o ajuste a um cenário não previsto.

\section{Procedimentos metodológicos}

Existem, de acordo com Barbosa Filho (1994), várias formas e procedimentos de estudar, trabalhar e empregar instrumentos de pesquisa. A maneira como o homem usa esses meios para desvendar o conhecimento, é chamado método. De acordo com Lakatos e Marconi (2001), método é o conjunto das atividades sistemáticas e racionais que, com maior segurança e economia, permite alcançar o objetivo, conhecimentos válidos e verdadeiros, traçando o caminho a ser seguido, detectando erros e auxiliando as decisões do cientista.

A investigação científica depende, para Gil (1999), de um conjunto de procedimentos intelectuais e técnicos para que seus objetivos sejam atingidos. O método científico corresponde ao conjunto de processos e operações mentais que se devem empregar na investigação. É a linha de raciocínio adotada no processo de pesquisa. 
Pesquisa significa procurar respostas para indagações propostas (SILVA; MENEZES, 2005). Para Gil (1999) a pesquisa tem um caráter pragmático. É um processo formal e sistemático de desenvolvimento do método científico. O objetivo fundamental da pesquisa é descobrir respostas para os problemas mediante o emprego de procedimentos científicos.

Esta pesquisa é classificada (SILVA; MENEZES, 2005):

- Do ponto de vista de sua natureza, ela é aplicada, pois gera conhecimentos para aplicação prática e dirigidos à solução de problemas específicos, envolvendo verdades e interesses locais;

- Do ponto de vista de seus objetivos, a pesquisa é descritiva, pois visa descrever as características de determinada população ou fenômeno ou o estabelecimento de relações entre variáveis;

- Com relação ao procedimento de pesquisa, adota-se o levantamento amostral ou survey.

O levantamento dos dados é efetuado através da pesquisa de campo, utilizando como instrumento de coleta de dados o questionário, constituído por uma série ordenada de perguntas fechadas e de múltipla escolha, que devem ser respondidas por escrito e sem a presença do entrevistador. Dentre as indústrias situadas no estado de São Paulo, a pesquisa recaiu sobre as que pertencem à jurisdição do CIESP (Centro das Indústrias do Estado de São Paulo), Diretoria Regional de Bauru e que estão localizadas no Distrito Industrial I do município de Bauru. Os dados coletados na pesquisa são apresentados em forma de quadros e figuras. As interpretações desses dados, que buscam promover o vínculo dos resultados com os objetivos propostos, foram realizadas juntamente com a apresentação dos dados obtidos.

O método escolhido para o estudo apresenta algumas limitações: abrangência da pesquisa às indústrias do Distrito Industrial I de Bauru que pertencem à jurisdição do CIESP, Diretoria Regional de Bauru, deixará à parte outras empresas da região, o que não permitirá generalizações das conclusões extraídas do estudo. Como o CIESP possui outras Diretorias Regionais, é possível que o grupo selecionado para a pesquisa não seja o mais representativo do universo estudado. Outro aspecto a ser considerado está relacionado à validade das respostas na coleta de dados para a obtenção dos melhores resultados. O pesquisado pode fornecer respostas falsas, que não traduzam suas reais opiniões, por diversas razões, conscientes e inconscientes. Com a finalidade de reduzir possíveis respostas falsas pelo pesquisado, as empresas não serão obrigadas à identificação. 


\section{Resultados do estudo}

Das empresas que estão listadas no cadastro da CIESP da Diretoria Regional Bauru no dia 25/01/2008, foi realizada a pesquisa nas indústrias que estão situadas no Distrito Industrial I de Bauru, totalizando 33 empresas. O questionário foi levado em mãos na empresa pelo autor, juntamente com uma carta de apresentação. Dado o prazo de cinco dias para a resposta, o autor direcionou-se às empresas efetuando o recolhimento dos questionários entregues. Foi solicitado o direcionamento do questionário aos proprietários das empresas. $\mathrm{Na}$ impossibilidade deste ser o sujeito respondente, solicitamos a entrega do questionário aos diretores, gerentes ou encarregados de prestar tais informações.

Das 33 empresas pesquisadas, 14 empresas, o que representa 42,42\% responderam corretamente o questionário e 19 empresas, o que representa 57,58\% não responderam, alegando tratar-se de informações sigilosas, por não terem tempo de responder e porque a pessoa responsável não se encontrava na empresa. Uma empresa nem quis atender o pesquisador. A Tabela 1 apresenta o retorno do questionário aplicado nas empresas.

Tabela 1 - Retorno do questionário aplicado nas empresas

\begin{tabular}{lcc}
\hline \multicolumn{1}{c}{ Questionários } & Quantidade & \% \\
\hline Respondidos & 14 & $42,42 \%$ \\
Não responderam por se tratar de informações sigilosas & 5 & $15,15 \%$ \\
Não responderam por não terem tempo & 11 & $33,34 \%$ \\
A pessoa responsável não se encontrava na empresa & 2 & $6,06 \%$ \\
Empresa não quis atender o pesquisador & 1 & $3,03 \%$ \\
\hline TOTAL & $\mathbf{3 3}$ & $\mathbf{1 0 0 \%}$ \\
\hline
\end{tabular}

Fonte: Dados da pesquisa.

Os grupos de questões e a ordem das perguntas foram elaborados para conduzir as respostas a explicar o cenário da empresa em relação à utilização de métodos quantitativos aplicados à mensuração do orçamento empresarial, com a finalidade de permitir a avaliação dos objetivos da pesquisa. As questões são fechadas e de múltipla escolha, devendo o respondente optar por uma ou mais alternativas, conforme a situação. Tais questões identificam os motivos que a empresa teve para a elaboração do orçamento; os motivos pelos quais levaram a empresa a utilizar o orçamento, sendo os motivos divididos em: motivo principal, motivo relevante, motivo secundário, motivo não relevante; quem são os responsáveis pela elaboração do orçamento na empresa; a periodicidade do orçamento empresarial; a maneira como a empresa define quantitativamente seu orçamento; os componentes que a empresa utiliza para a elaboração do orçamento do Balanço Patrimonial; como a empresa entende a utilidade do orçamento como um instrumento de mensuração 
quantitativa de operações; a comparação dos números reais com os orçados e a variação percentual aceitável pela empresa; o nível de dificuldade observado pela empresa para a operacionalização do orçamento, classificando cada afirmativa em dificuldade alta, média ou baixa; e a integração dos orçamentos dos diversos setores por programas computacionais.

Em relação à utilidade/importância das informações quantitativas mensuradas no orçamento para a empresa, separa-se a pesquisa em duas partes: se a empresa elabora ou não o orçamento empresarial periodicamente. Identificou-se que 57\% das empresas pesquisadas elaboram periodicamente o orçamento empresarial e $43 \%$ não o fazem. Nota-se que as empresas que não elaboram o orçamento estão entre as que possuem o menor nível de faturamento e também a menor quantidade de funcionários.

\subsection{Resultados da pesquisa acerca das empresas que elaboram o orçamento empresarial}

Neste item, serão realizadas as análises e discussões das perguntas respondidas relacionadas com as empresas que possuem o orçamento como instrumento de mensuração quantitativa e de gestão. O Quadro 2 apresenta os resultados dos motivos pelos quais levaram a empresa a utilizar o orçamento, sendo os motivos divididos em: motivo principal, motivo relevante, motivo secundário, motivo não relevante.

Quadro 2 - Motivos que levaram a empresa a utilizar o orçamento

\begin{tabular}{|l|c|c|c|c|}
\hline \multicolumn{1}{|c|}{ Motivos } & Principal & $\begin{array}{c}\text { Motivo } \\
\text { Relevante }\end{array}$ & $\begin{array}{c}\text { Motivo } \\
\text { Secundário }\end{array}$ & $\begin{array}{c}\text { Motivo Não } \\
\text { Relevante }\end{array}$ \\
\hline Adquirir mais conhecimento sobre o assunto. & $13 \%$ & $62 \%$ & $25 \%$ & $0 \%$ \\
\hline $\begin{array}{l}\text { Auxiliar na conquista de vantagem competitiva em } \\
\text { relação aos concorrentes. }\end{array}$ & $50 \%$ & $50 \%$ & $0 \%$ & $0 \%$ \\
\hline $\begin{array}{l}\text { "Precisávamos mensurar quantitativamente os } \\
\text { resultados pois estávamos perdidos". }\end{array}$ & $13 \%$ & $50 \%$ & $0 \%$ & $38 \%$ \\
\hline "Meus concorrentes utilizam o orçamento". & $13 \%$ & $13 \%$ & $37 \%$ & $37 \%$ \\
\hline $\begin{array}{l}\text { Proporcionar melhoramentos no processo de } \\
\text { tomada de decisões. }\end{array}$ & $75 \%$ & $25 \%$ & $0 \%$ & $0 \%$ \\
\hline
\end{tabular}

Fonte: Dados da pesquisa.

A pesquisa mostra que:

- $13 \%$ das empresas que elaboram o orçamento empresarial consideram esta afirmativa como o motivo principal; $62 \%$ como motivo relevante e $25 \%$ consideram o motivo secundário.

- $50 \%$ das empresas que elaboram o orçamento empresarial consideram esta afirmativa como o motivo principal e os outros $50 \%$ como motivo relevante. Isso demonstra a importância da mensuração quantitativa do orçamento empresarial 
para auxiliar nas tomadas de decisões em seus mais variados aspectos em relação aos concorrentes.

- $13 \%$ das empresas que elaboram o orçamento empresarial consideram esta afirmativa como o motivo principal e $49 \%$ como motivo relevante; $38 \%$ dos pesquisados consideram essa afirmativa como um motivo não relevante. Nota-se que a maioria das empresas pesquisadas necessitam de instrumentos de mensuração quantitativa para o planejamento e controle do negócio. Das empresas que consideram um motivo não relevante, nota-se que elas são as maiores em faturamento e quantidade de funcionários.

- $13 \%$ das empresas que elaboram o orçamento empresarial consideram esta afirmativa como o motivo principal e 13\% como motivo relevante; $37 \%$ dos pesquisados consideram essa afirmativa como um motivo secundário e $37 \%$ um motivo não relevante. Nota-se que a maioria das empresas pesquisadas não se preocupa se seus concorrentes utilizam o orçamento empresarial e que a sua maioria estão entre as maiores em faturamento e número de funcionários.

- $75 \%$ das empresas que elaboram o orçamento empresarial consideram esta afirmativa como o motivo principal e $25 \%$ como motivo relevante. Isso demonstra a importância do orçamento empresarial para as empresas na busca por melhorar seu processo decisório.

As Figuras de 1 a 5 apresentam os resultados da pesquisa sobre os responsáveis pela elaboração do orçamento empresarial, sua periodicidade, a maneira como é definido tal instrumento de mensuração quantitativa, o que ela utiliza para a elaboração do Balanço Patrimonial e como a empresa entende a utilidade do orçamento empresarial. Para tal, as questões respondidas apresentam as preferências e os respondentes assinalaram uma ou mais alternativas.

Figura 1 - Responsáveis pela elaboração do orçamento na empresa 


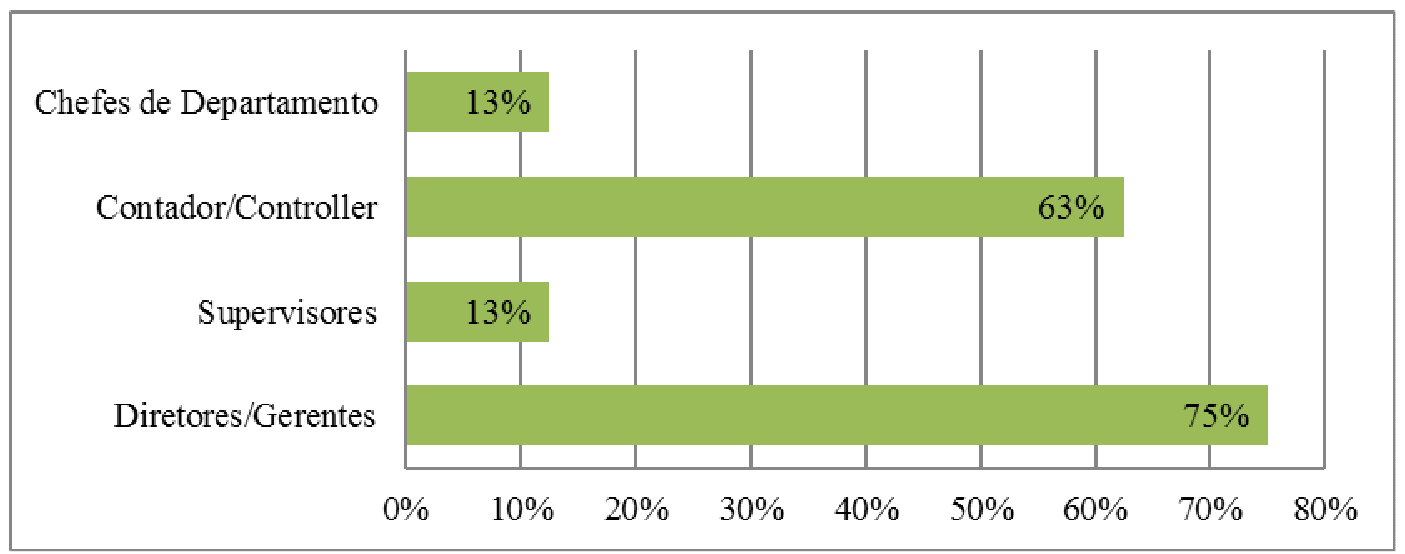

Fonte: Dados da pesquisa.

Percebe-se que na maioria das empresas pesquisadas, os responsáveis pela elaboração do orçamento empresarial são os diretores/gerentes e os contadores/controller, desenvolvendo esta atividade em conjunto. Nota-se que os diretores/gerentes definem os parâmetros quantitativos do orçamento e os contadores/controller os transformam na peça orçamentária e fazem o acompanhamento e controle. A Figura 2 apresenta os resultados da pesquisa sobre a periodicidade do orçamento empresarial. A pesquisa demonstra que a maioria das empresas elabora o orçamento empresarial para o próximo ano. Nota-se que as empresas encontram dificuldades de elaboração de orçamentos superiores a um ano.

Figura 2 - Periodicidade do orçamento empresarial

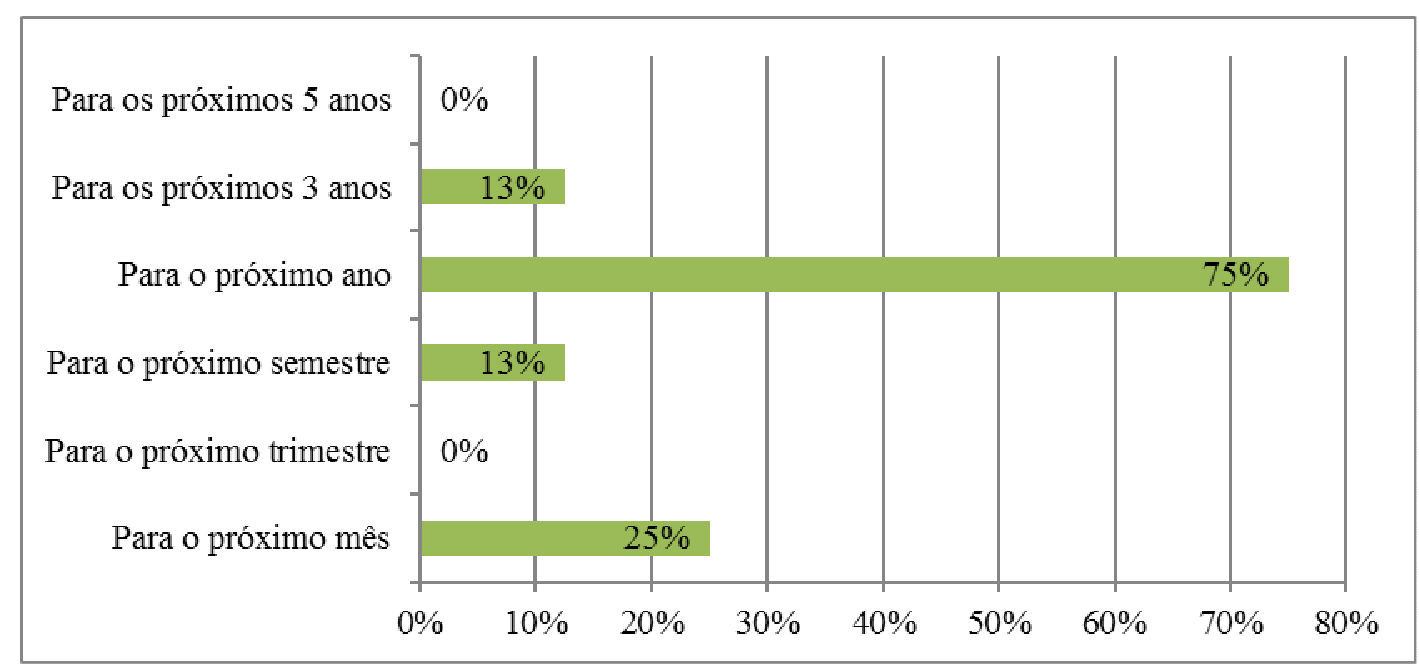

Fonte: Dados da pesquisa.

Das poucas empresas que elaboram o orçamento para mais de um ano encontram-se as maiores em faturamento e quantidade de funcionários. Isso mostra que estas empresas possuem mais visão do futuro que as demais, antecipando cenários para o adequado direcionamento de esforços, com a finalidade de atingir a meta estabelecida pela empresa. A 
Figura 3 apresenta os resultados da pesquisa sobre a maneira como a empresa define quantitativamente seu orçamento.

Figura 3 - Maneira como é definido quantitativamente o orçamento empresarial

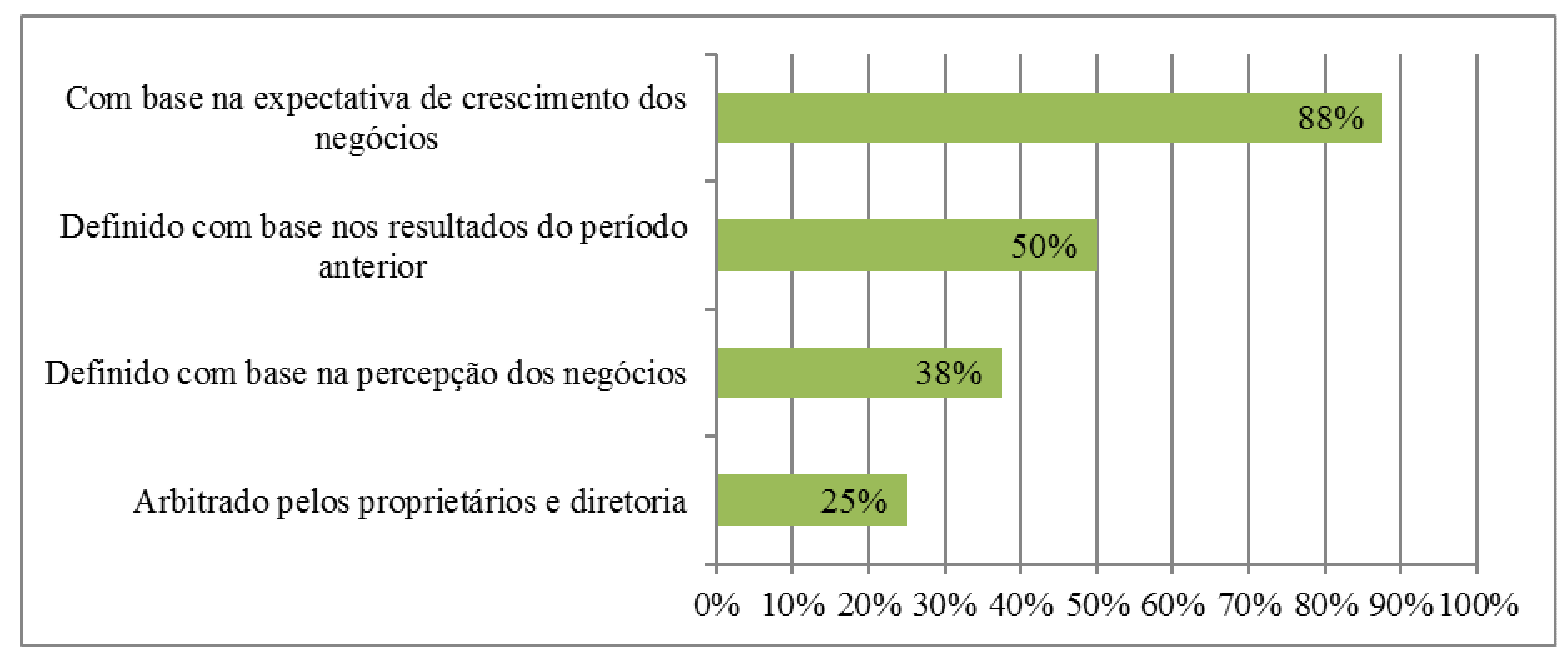

Fonte: Dados da pesquisa.

A pesquisa demonstra que as empresas definem seu orçamento principalmente com base na expectativa de crescimento dos negócios, mas também definem com base os resultados do período anterior. A Figura 4 apresenta os resultados da pesquisa sobre os componentes que a empresa utiliza para a elaboração do orçamento do Balanço Patrimonial.

Figura 4 - Componentes que a empresa utiliza para a elaboração do orçamento do Balanço Patrimonial

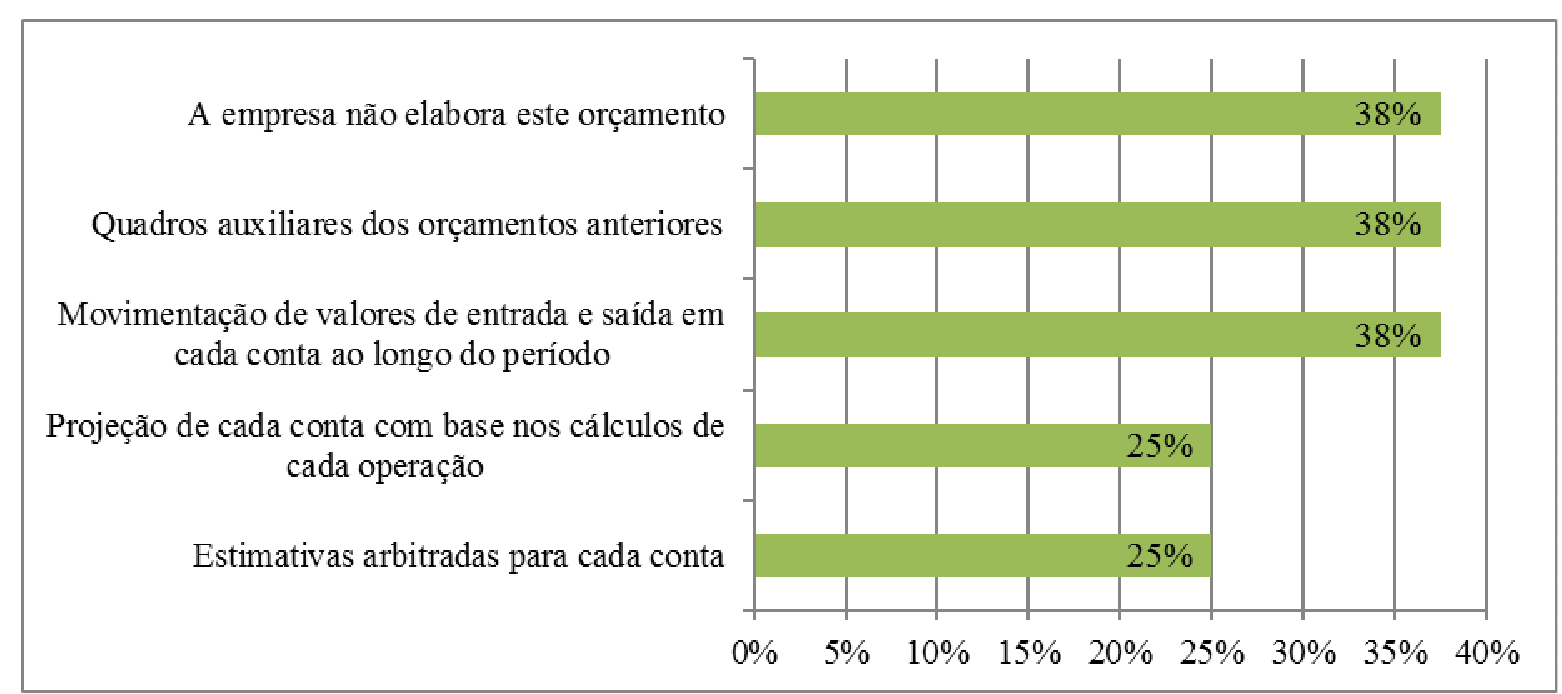

Fonte: Dados da pesquisa.

A pesquisa mostra que as empresas elaboram seu orçamento do balanço patrimonial principalmente com base na movimentação de valores de entrada e saída em cada conta ao longo do período e nos quadros auxiliares dos orçamentos anteriores. Algumas assinalaram que definem os valores de forma arbitrária para cada conta e também efetuam projeção de 
cada conta com base nos cálculos de cada operação. Nota-se que algumas das empresas pesquisadas não elaboram este orçamento.

Percebe-se considerável participação de empresas que não elaboram o orçamento do balanço patrimonial, o que pode proporcionar a falta de visão das contas desta demonstração contábil e da análise dos indicadores financeiros projetados. Isso pode prejudicar o planejamento da liquidez, rentabilidade, endividamento, giro e solvência empresarial. A Figura 5 apresenta os resultados da pesquisa sobre como a empresa entende a utilidade do orçamento como um instrumento de mensuração quantitativa de operações.

Figura 5 - Utilidade do orçamento

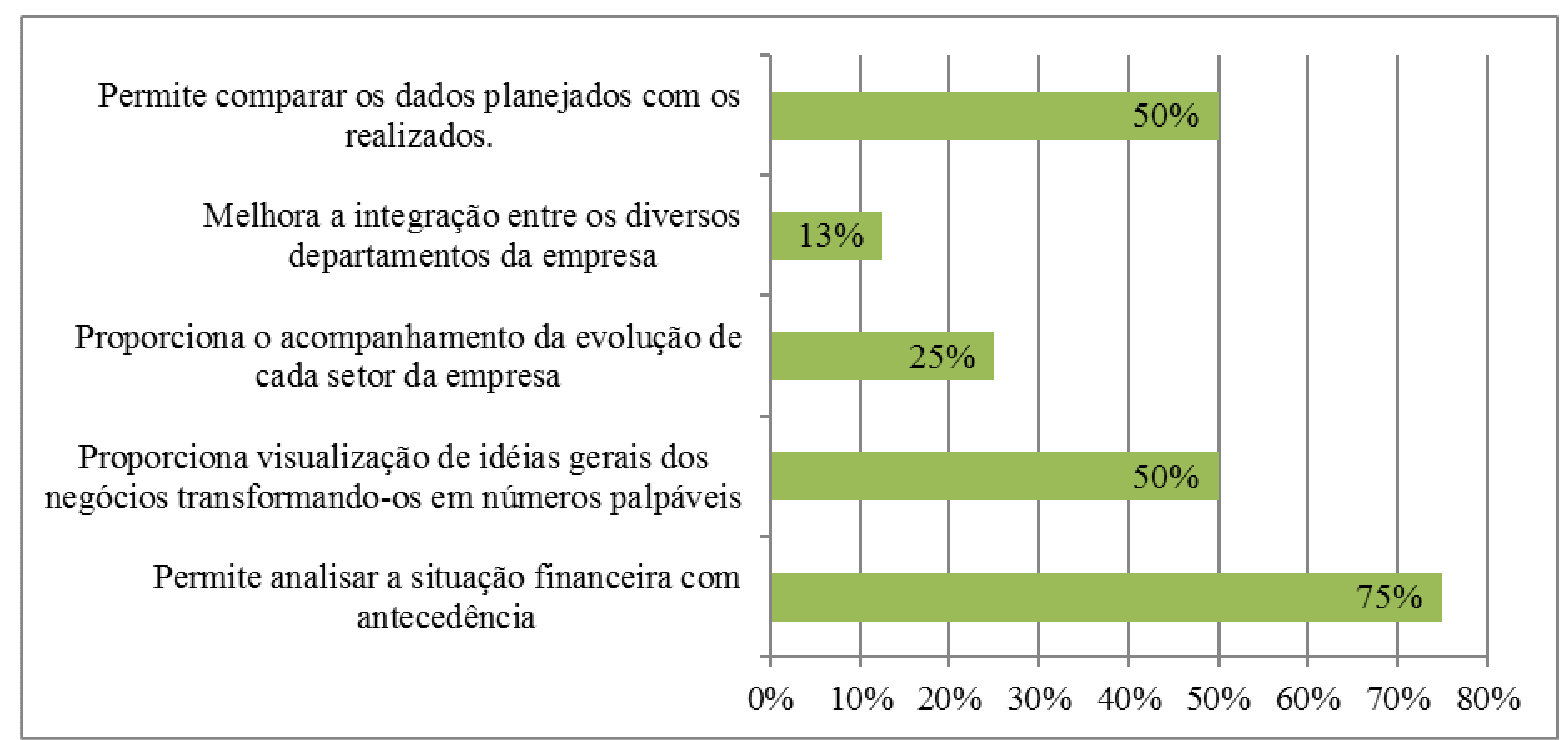

Fonte: Dados da pesquisa.

A pesquisa mostra que as empresas entendem o orçamento como instrumento de mensuração quantitativa de operações principalmente porque eles permitem analisar a situação financeira com antecedência, também por proporcionar visualização de ideias gerais dos negócios transformando-os em números palpáveis e por entenderem que ele permite comparar os dados planejados com os realizados.

Alguns assinalaram que eles entendem que ele proporciona o acompanhamento da evolução de cada setor da empresa e também entendem que o orçamento melhora a integração entre os diversos departamentos da empresa. Nota-se deficiência nas empresas pesquisadas em relação a integração que o orçamento deve proporcionar aos departamentos da empresa. A Figura 6 apresenta os resultados da pesquisa sobre a comparação dos números reais com os orçados e a variação percentual aceitável pela empresa. 
Figura 6 - Comparação dos números reais com os orçados e a variação percentual aceitável pela empresa

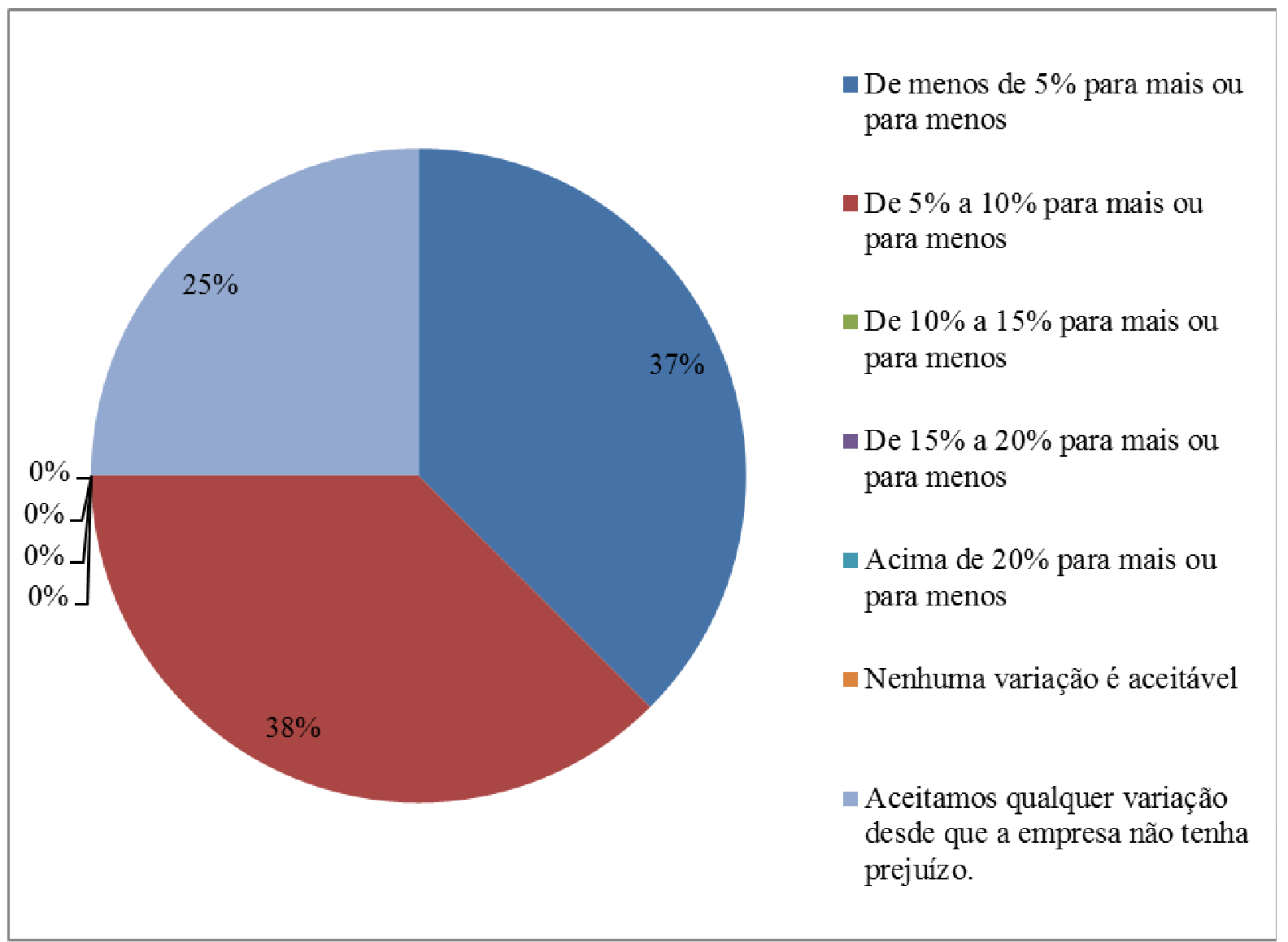

Fonte: Dados da pesquisa.

A pesquisa demonstra que $38 \%$ das empresas aceitam uma variação percentual de $5 \%$ a $10 \%$ entre o orçado e o realizado; $37 \%$ aceitam uma variação percentual de menos de 5\% para mais ou para menos e $25 \%$ aceitam qualquer variação desde que a empresa não tenha prejuízo. Isso mostra que as empresas pesquisadas não aceitam grandes distorções do orçado versus o realizado e que elas buscam não incorrer em prejuízo quando se aceita qualquer variação. O Quadro 3 evidencia o nível de dificuldade observado pela empresa para a operacionalização do orçamento, classificando cada afirmativa em dificuldade alta, média ou baixa.

Quadro 3 - Nível de dificuldade observado pela empresa para a operacionalização do orçamento

\begin{tabular}{|l|c|c|c|}
\hline \multicolumn{1}{|c|}{ Nível de dificuldade } & Alto & Médio & Baixo \\
\hline Elaboração da estratégia e das metas a serem alcançadas pela empresa. & $87 \%$ & $13 \%$ & $0 \%$ \\
\hline Identificação dos indicadores de cada departamento a serem avaliados pela empresa. & $49 \%$ & $38 \%$ & $13 \%$ \\
\hline Identificação e interpretação dos dados gerados pelo orçamento. & $13 \%$ & $62 \%$ & $25 \%$ \\
\hline Motivar e convencer todos a trabalhar com o modelo. & $25 \%$ & $37 \%$ & $38 \%$ \\
\hline Equalizar as análises estratégicas com as operacionais. & $62 \%$ & $38 \%$ & $0 \%$ \\
\hline
\end{tabular}

Fonte: Dados da pesquisa. 
A pesquisa mostra que em relação ao nível de dificuldade observado pela empresa para operacionalização do orçamento:

- $87 \%$ das empresas encontram um alto nível de dificuldades em relação à elaboração da estratégia e das metas a serem alcançadas pela empresa e $13 \%$ encontram um médio nível de dificuldades. Fica evidenciada a dificuldade das empresas na elaboração do planejamento e definição das metas, tornando-se um desafio aos gestores obterem da "visão de futuro", necessária para antecipar dificuldades.

- $49 \%$ das empresas encontram um alto nível de dificuldades em relação à identificação dos indicadores de cada departamento a serem avaliados pela empresa; $38 \%$ encontram um médio nível de dificuldades enquanto que $13 \%$ encontram um nível baixo de dificuldades. Percebe-se, portanto, que a maioria das empresas pesquisadas possui dificuldades na identificação de indicadores de desempenho por departamento, o que seria um importante passo na medição da empresa para a tomada de decisões.

- $13 \%$ das empresas encontram um alto nível de dificuldades em relação à identificação e interpretação dos dados gerados pelo orçamento; $62 \%$ encontram um médio nível de dificuldades enquanto que $25 \%$ encontram um nível baixo de dificuldades. Nota-se então que a maioria das empresas pesquisadas possui dificuldades do nível médio e baixo na identificação e interpretação dos dados gerados pelo orçamento, o que demonstra a facilidade de identificação e interpretação do que se espera do orçamento pelos departamentos para a execução das tarefas.

- $25 \%$ das empresas encontram um alto nível de dificuldades em relação a motivar e convencer os colaboradores da empresa a trabalhar com o modelo; $37 \%$ encontram um médio nível de dificuldades enquanto que 38\% encontram um nível baixo de dificuldades.

- $62 \%$ das empresas encontram um alto nível de dificuldades em relação a equalizar as análises estratégicas com as operacionais e 38\% encontram um médio nível de dificuldades.

Percebe-se certa resistência dos colaboradores da empresa em trabalhar com o orçamento empresarial, principalmente as que possuem maior quantidade de funcionários, o que nos leva a entender que quanto maior a quantidade de funcionários na empresa, maior será a dificuldade de motivar e convencer tais profissionais a trabalhar com o modelo. 
Outro questionamento foi efetuado pela pesquisa: O programa computacional utilizado na elaboração do orçamento empresarial permite a integração dos orçamentos dos diversos setores da empresa e a análise de tais informações? A pesquisa obteve que $75 \%$ das empresas possui programa computacional que permite a integração dos orçamentos dos diversos setores e proporciona a análise dessas informações e $25 \%$ não possui tal programa que proporcione esta integração.

\section{Considerações finais}

O planejamento, a execução e o controle dos negócios empresariais estão diretamente relacionados com a sobrevivência das empresas no atual ambiente competitivo, onde o gestor que produzir informações quantitativas sobre o futuro da organização poderá diagnosticar possíveis dificuldades em cenários futuros, podendo, no presente, tomar decisões que irão proporcionar resultados desejados. As indústrias normalmente necessitam de relatórios quantitativos de previsão de resultados e a elaboração do planejamento orçamentário facilita o processo de tomada de decisão.

O orçamento empresarial apresenta-se como importante instrumento quantitativo para a gestão dos negócios. O objetivo deste trabalho foi investigar como as indústrias, que estão situadas no Distrito Industrial I da cidade de Bauru, compreendidas pela jurisdição do CIESP Diretoria Regional de Bauru, utilizam o orçamento como instrumento quantitativo de mensuração para o planejamento e tomada de decisão. Após análise e discussão dos resultados da pesquisa nas empresas, pode-se concluir que:

- Existe a predominância de empresas do tipo limitada (Ltda.), de capital fechado e nacional, e sua contabilidade efetuada dentro da empresa. A maioria possui até 50 funcionários, mas as que possuem mais de 200 funcionários têm grande representatividade. Mais da metade das empresas possui abrangência de mercado nacional e internacional;

- Encontra-se alto nível de dificuldades em relação a elaboração das estratégias e metas a serem alcançadas, bem como seu alinhamento com as operações;

- A maioria possui dificuldades na identificação de indicadores de desempenho, o que seria um importante passo para a medição da empresa;

- Observou-se a incidência do orçamento empresarial em 57\% das empresas pesquisadas. Estas possuem o maior nível de faturamento e também a maior 
quantidade de funcionários. Elas compreendem, utilizam e dão mais importância aos instrumentos de mensuração quantitativa e de gestão;

- É importante, para a implantação do planejamento orçamentário, a classificação adequada dos dados, para o gerenciamento da informação;

- Os principais responsáveis pela elaboração do orçamento nas empresas são os Diretores/Gerentes e Contador/Controller, desenvolvendo esta atividade em conjunto;

- Predominam as empresas que elaboram o orçamento para os próximos doze meses. Definem o orçamento com base na expectativa de crescimento dos negócios, na utilização de resultados do período anterior e a percepção sobre os negócios;

- Para a elaboração do orçamento empresarial e a disponibilização de suas informações aos usuários, é necessário o aumento do nível de conhecimento dos administradores da empresa, ter um programa computacional que permita o tratamento eletrônico dos dados, gerando informações para a elaboração do orçamento, interesse daqueles que utilizam tais informações e maior conhecimento da realidade interna da empresa.

- Metade das empresas julga suas informações, para a elaboração do planejamento orçamentário, entre péssimas e regulares, dificultando preliminarmente um trabalho de implantação.

O planejamento orçamentário apresenta-se como importante instrumento de mensuração quantitativa por permitir analisar a situação financeira com antecedência, por proporcionar visualização de ideias gerais dos negócios transformando-os em números palpáveis e por permitir comparar os dados planejados com os realizados.

O estudo limita-se a apresentar dados das empresas situadas em um determinado distrito industrial, não podendo generalizar estes resultados para os demais distritos industriais, mas, pode-se comparar os resultados obtidos com os de outros distritos industriais. Uma sugestão para estudos futuros é a realização de pesquisa semelhante a esta em setores de atividade econômica.

\section{Referências}

ANTHONY, R. N.; GOVINDARAJAN, V. Sistema de controle gerencial. São Paulo: Atlas, 2002. 
BARBOSA FILHO, M. Introdução à pesquisa: métodos, técnicas e instrumentos. João Pessoa: A União, 1994.

CIESP. Centro das Indústrias do Estado de São Paulo. Disponível em <www.ciesp.org.br>. Acesso: 22/5/2007.

GIL, A. C. Métodos e técnicas de pesquisa social. 5 ed. São Paulo: Atlas, 1999. . Como elaborar projetos de pesquisa. São Paulo: Atlas, 1996.

HECKERT, J.B.; WILLSON, J.D. Business budgeting and control. Nova York: The Ronald Press, 1967.

HOJI, M. Administração financeira: uma abordagem prática. São Paulo: Atlas, 2004.

KOHLER, E. L. A dictionary for accountants. Nova Jersey: Prentice-Hall, 1970.

LAKATOS, E. M.; MARCONI, M. A. Fundamentos de metodologia científica. São Paulo: Atlas, 2001.

LUNKES, R. J. Manual de orçamento. São Paulo: Atlas, 2008.

MARCONI, M. A.; LAKATOS, E. M. Técnicas de pesquisa. São Paulo: Atlas, 2002.

MEYER, J. Gestion Budgétaire. Paris: Dunod, 1969.

OLIVEIRA, C. E. Planejamento orçamentário empresarial de indústrias do distrito industrial I de Bauru. Dissertação (Mestrado em Engenharia de Produção). Faculdade de Engenharia de Bauru, UNESP, 2008.

PASSARELLI, J. Orçamento empresarial: como elaborar e analisar. São Paulo: IOBThomson, 2003.

SANVICENTE, A.Z.; SANTOS, C.C. Orçamento na administração de empresas. São Paulo: Atlas, 1983.

SILVA, E. L.; MENEZES, E. M. Metodologia da pesquisa e elaboração de dissertação. Florianópolis: UFSC, 2005.

SOBANSKI, J.J. Prática de orçamento empresarial. São Paulo: Atlas, 2000.

TUNG, N. H. Orçamento empresarial no Brasil. São Paulo: Edições Universidade-empresa Ltda., 1975.

ZDANOWICZ, J. E. Orçamento operacional. Porto Alegre: Sagra, 1983. 